\title{
Joint use of habitat by red kangaroos and shorthorn cattle in arid central Australia
}

\section{L. DUDZINSKI*}

Division of Mathematics and Statistics, CSIRO, PO Box 1965, Canberra City, Australia 2601

W. A. LOWE $\dagger$

Division of Land Resources Management, CSIRO, Alice Springs, Australia 5750

W. J. MÜLLER

Division of Mathematics and Statistics, CSIRO, PO Box 1965, Canberra City, Australia 2601

BOBBI S. LOW

School of Natural Resources, University of Michigan, Ann Arbor, Michigan, USA 48104

\section{Abstract}

The distribution of cattle and red kangaroos among the major communities of a $170 \mathrm{~km}^{2}$ paddock in central Australia was determined from 108 and 82 air surveys respectively over a four and a half year period. Fifty-nine surveys of each species were used in this report. Changes in use of the communities by the two species were analysed in relation to forage conditions using linear regression techniques. The two species showed trends in time of use of the open and wooded communities. Kangaroos used the mulga-perennial community (groved Acacia woodland with a shrub and perennial grass understorey) during good forage conditions and moved to the drought refuge open communities when forage conditions deteriorated. Cattle, on the other hand, used the open communities during good forage conditions and tended to move to the mulga communities and the hills when drought began. Mulga-annual (ungroved Acacia woodland with short grass and forb understorey) was the only major community which showed no clear linear relationship be-

\footnotetext{
'Present address: Division of Wildlife Research, CSIRO, PO Box 84, Lyneham, Australia 2602

${ }^{\dagger}$ Present address: c/o Conservation Commission, Alice Springs, Australia 5750
}

tween kangaroo use and forage conditions. This might be a buffer area from which kangaroos come and go as other areas become more attractive as feeding areas. Cattle, however, show some preference for mulga annual during medium forage conditions. There appears to be little spatial interaction by the two species except during drought when kangaroos concentrate on the open communities and some cattle continue to feed in these communities. Community selection seems to be determined mainly by forage conditions, as there is no evidence that one species attracts or repels the other in spatial terms. In the conditions observed, the two species successfully coexisted with some control of numbers of cattle by man.

\section{Introduction}

The utilization of particular habitats by two or more species of grazing herbivores may result in competition between the two species for the available forage resource. Gwynne \& Bell (1968) and Hirst (1975) have shown that African ungulate species use the available habitats and forage resource quite differently due to different anatomical structure, and consequently different forage preferences and timing of use of the habitats. In central Australia two herbivores, the recently introduced domestic cow (Bos taurus) and the native red kangaroo (Megaleia rufa) have coexisted in the broad area of mulga (Acacia aneura) woodlands and adjacent open plains and hills for about 100 years (Low 1978), and indeed kangaroo numbers have increased considerably (Newsome 1975).

The habitat preferences of cattle and kangaroos were determined from aerial surveys of a large paddock $\left(170 \mathrm{~km}^{2}\right)$ north-west of Alice Springs, and reported in a series of papers, e.g. Low \& Low (1975); Low et al. (1981a) and Low 
et al. (1981b). These previous papers showed that the pattern of use of the available plant communities by cattle and kangaroos varied under different rainfall and forage conditions. In this paper we compare the utilization of the available plant communities by cattle and kangaroos to examine more closely the potential interactions of the two species.

\section{Methods}

The field methods and study site are described in detail by Low et al. (1981 a,b). From 1970 to 1975, 108 cattle and 82 kangaroo aerial surveys of the paddock were made. The transect width for cattle observations was constant $(800 \mathrm{~m}$ each side of plane) irrespective of community, with observations being made from an altitude of $120 \mathrm{~m}$. However, kangaroo flights were generally at about $30 \mathrm{~m}$, and effective transect widths varied with the degree of obstruction of visibility of kangaroos by shrubs in each community. Visibility was found to be over $800 \mathrm{~m}$ for each observer in the open communities (i.e. complete counts were obtained), $450 \mathrm{~m}$ in semi-open communities and $200 \mathrm{~m}$ in heavily wooded communities.

In order to compare cattle and kangaroo distributions on the paddock using similar amounts of information for each species and over the same range of forage conditions, it was necessary to identify suitable pairs of surveys. Thus 67 cattle-kangaroo pairs of surveys, most of which were separated from each other by one week or less, and all with no intervening change in weather or abrupt changes in forage conditions, were selected. Eight of these 67 pairs were not included in this study because kangaroo numbers were under-estimated due to cloud, or because an accurate percentage distribution of kangaroos across communities could not be obtained due to low numbers. Consequently, the study contained 59 pairs of surveys, with cattle and kangaroos being sur-veyed at the same time on 23 occasions. In most intervals between successive paired surveys there were changes in climatic conditions, principally in rain, wind or temperature, and we assumed these changes minimized any temporal effect.

Only the major communities on the paddock have been considered. These were, for cattle: foothill fans ( $5 \%$ of paddock area), flood plains (13\%), gilgaied plains (5\%) and woodland $(13 \%)$, which were combined for analyses to form open communities (36\%); mulgaperennial grass $(26 \%)$, hills $(8 \%)$ and mulgaannual grass $(27 \%)$. As kangaroos did not use the foothill fans and hills, these two communities were not considered for this species. The other communities were the same. Full details of all communities are given in Low et al. (1981a).

Percentages of cattle and kangaroos in each community on the paddock were calculated for each survey and were angular transformed for analysis. These angles were then backtransformed to percentages in all figures. Angular transformation stabilized variances and improved linearity of regressions. Forage growth state scores (1-3) and quantity scores (1-4) were obtained for each community at each survey (Low et al. 1981a). At each survey a combined forage index (FI) was obtained for each community by deriving a single index from the growth state and quantity scores shown in Table 1.

In support of this subjective matrix, the combined FI regressed on cumulative rainfall and calculated water loss, similar to Newsome's (1966) drought index, showed a highly significant correlation $(P<0.001)$. A single value of FI for the whole paddock was then calculated as the mean over communities weighted by community area.

Simple linear and quadratic regressions were obtained between the transformed percentage of each species in each community or group of communities and FI, using estimated numbers of animals present in the whole paddock as weights in the regressions. A test of independence of spatial distribution between the two species was carried out for mobs within the major communities for each of the

TABLE 1 . The subjectively estimated forage index

\begin{tabular}{lllll}
\hline \multirow{5}{*}{ Growth } & state & & \\
& 1 & 2 & 3 & \\
\hline 1 & 1 & 1.5 & 2 & Abundant \\
2 & 1 & 2 & 3 & $\downarrow$ \\
3 & 2 & 3 & 4 & Sparse \\
4 & 2.5 & 3.5 & 5 & \\
& Green & $\rightarrow$ & Dry & \\
\hline
\end{tabular}


(a)
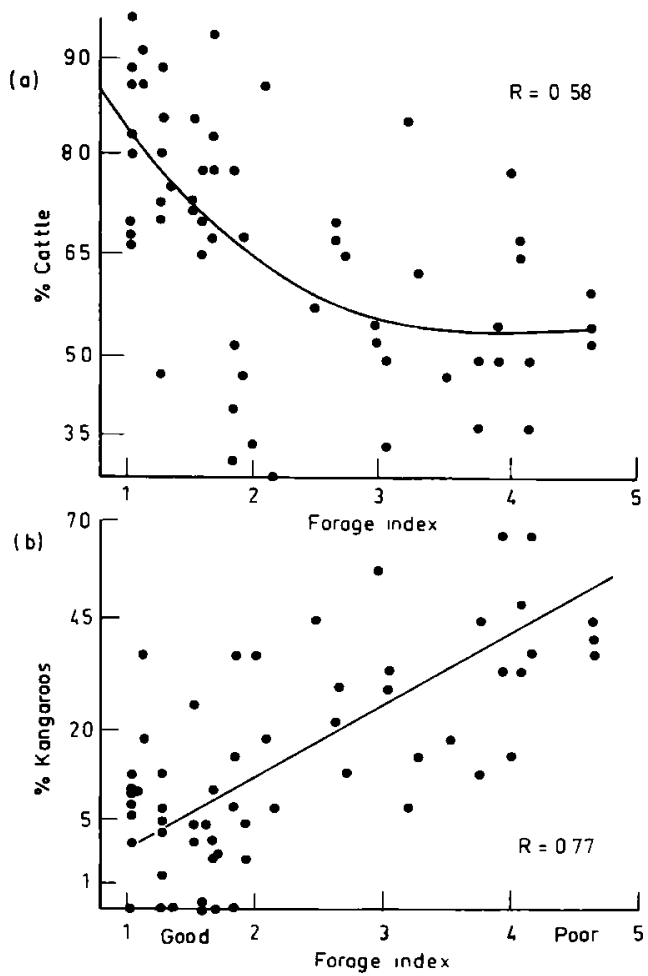

FIG. 1. Relationship between percentage of (a) cattle and (b) kangaroos in the open communities and forage index. $R$ = multiple correlation.

23 occasions when concurrent observations were made. The test was based on nearestneighbour distances between mobs of cattle and kangaroos.

\section{Results}

The relationships between cattle and kangaroo percentages and forage index $(\mathrm{FI})$ for open communities are presented in Fig. 1(a,b), and

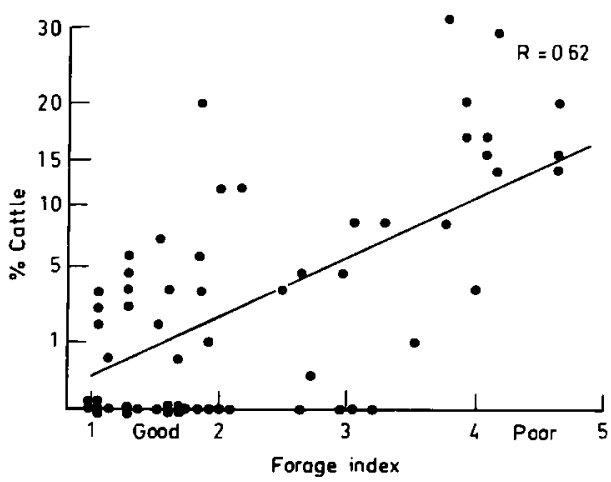

FIG. 2. Relationship between percentage of cattle in the hills and forage index. $\mathbf{R}=$ multiple correlation.
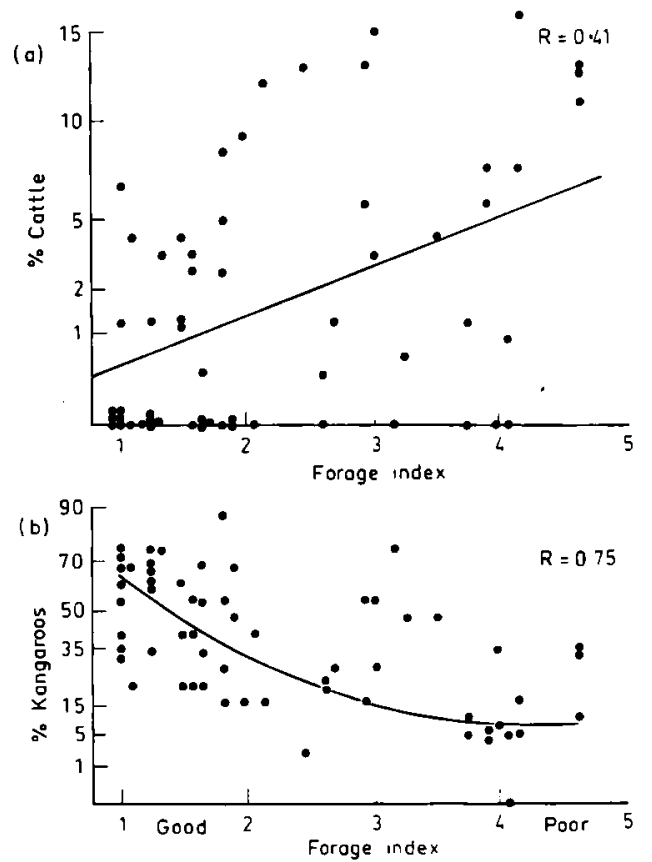

FIG. 3. Relationship between percentage of (a) cattle and (b) kangaroos in mulga-perennial grass community and forage index. $\mathrm{R}=$ multiple correlation.
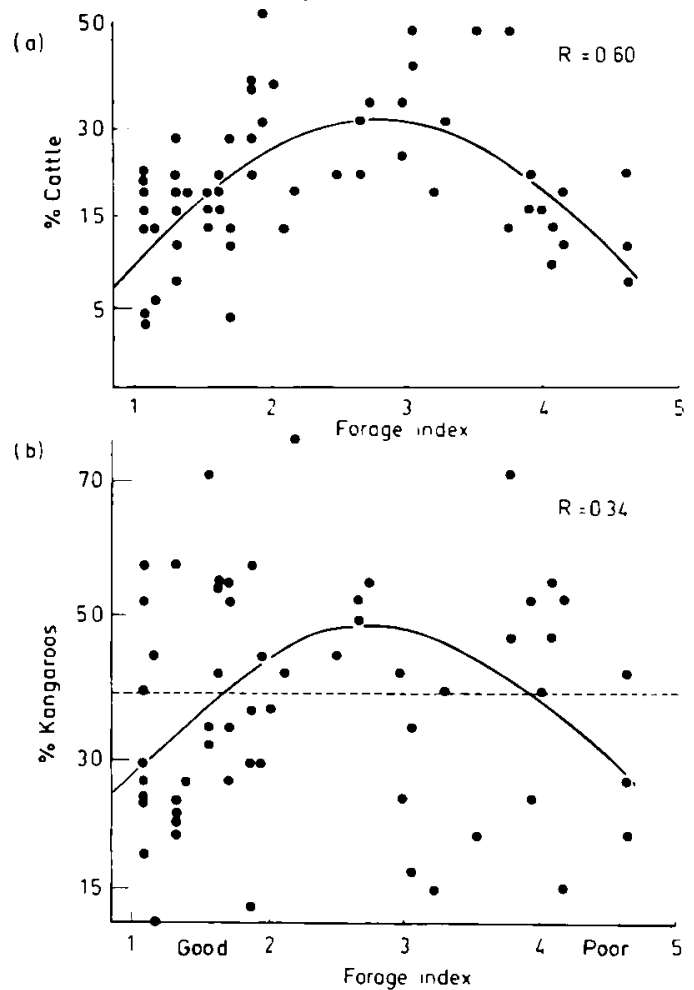

FIG. 4. Relationship between percentage of (a) cattle and (b) kangaroos in mulga-annual grass community and forage index. Both the mean lcvel (broken linc) and the fitted quadratic trend (solid line) are shown for kangaroos. $\mathrm{R}=$ multiple correlation. 
TABLE 2. Simple linear regression slopes of changes in angular-transformed percentage of cattle and kangaroos in the major communities on forage index

\begin{tabular}{lcc}
\hline Community & \multicolumn{2}{l}{ Rate of change in community preference } \\
& $\begin{array}{c}\text { Cattle } \\
\text { Slope } \pm \text { s.e. }\end{array}$ & Slope \pm s.e. \\
& & Not used \\
\hline Foothill fans & $-1.38 \pm 1.13$ & $4.39 \pm 0.76$ \\
Flood plains & $-1.41 \pm 0.83$ & $2.49 \pm 0.62$ \\
Gilgai & $-0.38 \pm 0.95$ & $8.67 \pm 0.92$ \\
Woodland & $-2.30 \pm 0.95$ & $10.11 \pm 1.09$ \\
Open communities* & $-4.82 \pm 1.02$ & Not used \\
Hills & $5.46 \pm 0.90$ & $-10.28 \pm 1.27$ \\
Mulga-perennial & $2.87 \pm 0.80$ & Quadratic \\
Mulga-annual & Quadratic &
\end{tabular}

* Obtained by pooling data from the first four communities. The quadratic component for cattle is only marginally significant, so the linear regression slope for comparison with kangaroos has been given.

details of the linear regressions are given in Table 2. Cattle preference for open communities was negatively related to FI, i.e. they preferred the open communities when forage conditions were good and moved out of them when forage conditions were poor. Conversely, kangaroo use of the open communities was positively related to $\mathrm{FI}$.

The percentage of cattle in both the hills and mulga-perennial grass significantly increased as forage conditions deteriorated $(P<0.001)$ (Figs 2 and 3a). There was also a highly significant linear relation to FI for percentage of kangaroos in the mulga-perennial $(56 \%$ of variation; $\mathrm{P}<0.001$ ) (Fig. 3b), which was opposite in trend to that of the cattle. No kangaroos were observed in the hills.

While cattle displayed a definite preference for the mulga-annual grass community when the forage index was medium (2-3), (quadratic regression significant at $P<0.001$ ), changes in the percentages of kangaroos in mulga-annual did not show as clear a pattern in response to forage index changes with the quadratic regression only significant at $P<0.05$ (Fig. 4a, b).

A summary of trends in use of communities or groups of communities by the two species relative to the forage index is shown in Fig. 5. These trends were obtained from the fitted regression relationships in Figs 1-4.

The test of spatial interaction of the two

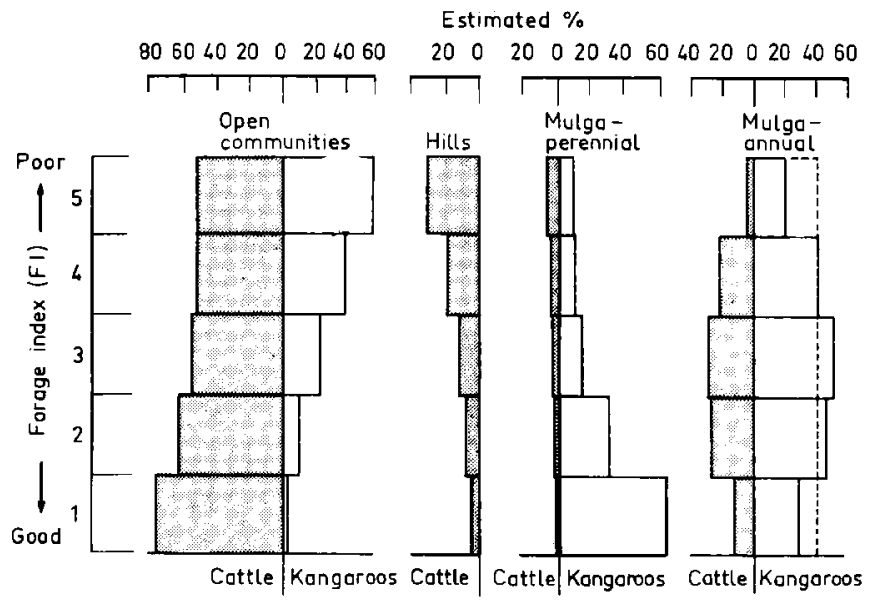

FIG. 5. Relationship of estimated percent of cattle (shaded) and kangaroos (unshaded) in the major communities to forage index. The two possible interpretations of trends for kangaroos in mulga-annual are represented; the mean level by a broken line and the fitted quadratic trend by solid lines. 
species in the major communities on the 23 occasions when cattle and kangaroos were surveyed concurrently failed to detect, on all occasions, significant departure from the hypothesis of the two species being independently distributed. That is, there was no suggestion that one species attracts or repels the other in spatial terms.

\section{Discussion and conclusions}

Figure 5 shows that the broad trends of the community distribution of the two species in relation to changes in forage are definitely established, though the possible temporal character of the data should lead to cautious regard of individual probability levels. It is also apparent from Fig. 5 that there is little concurrent competition occurring in general use of the communities by cattle and kangaroos. Some cattle leave the open communities after forage has dried off and been eaten and move to the hills and mulga-perennial grass communities during drought. Kangaroos, on the other hand, mostly move out of the mulga-perennial community, used in good forage conditions, and transfer to the open communities during drought periods. Thus there is generally a substitution of one animal species by the other in use of the communities, which is in agreement with Newsome (1975).

Kangaroos tend to respond more markedly to changes in forage conditions as shown in Table 2, where the slopes of the regressions indicate the rate of change in use. In all communities except perhaps in mulga-annual grass, community use increases or decreases with FI over the whole range. However in mulga-annual, cattle move in to feed on browse species (mulga, Acacia aneura) and witchetty ( $A$. kempeana) when forage conditions are moderate, hence a marked quadratic relationship with FI (Fig. 4a). The relationship between kangaroos and FI in mulga-annual is not clear, with only a marginally significant quadratic trend (Fig. 4b) due to a disruption in pattern at the mid-range of forage conditions $(F I=2-3)$. Our data suggest two alternative explanations describing use of this community by kangaroos. Firstly, there may be a mean use of about $40 \%$ which is not related to forage conditions (broken lines, Figs $4 b$ and 5). Alternatively, it could be that during good and poor forage conditions the use of mulgaannual is not related to forage index, whereas when forage conditions are moderate no low usage of this community by kangaroos occurs. Field observations of kangaroo movements in the study area during drought and following good rains suggest that the mulga-annual may be a buffer area between the mulga-perennial community and the open communities, with kangaroos moving through it like a corridor or using it as a refuge when other communities are not suitable. Newsome (1975) also found kangaroos in mulga-annual under a variety of forage conditions.

Our data suggest that there are two circumstances when competition between the two species might occur: in open communities during droughts when approximately $50 \%$ of kangaroos and $45 \%$ of cattle were found in these communities; and in mulga-annual during moderate forage conditions, when cattle use is high and kangaroo use is considerable, as discussed above. Otherwise there is little concurrent competition between cattle and kangaroos in the use of the major communities. Competition for forage is limited, since cattle eat more species of grass, herbage and trees than kangaroos, while kangaroos depend on fewer species of green grass (Chippendale 1968; Low \& Low 1975; Newsome 1975).

In conclusion, Newsome (1975) postulated that the utilization of the basic plant communities by cattle and red kangaroos is inversely related, and our data confirms this. Also we found no evidence that either species concurrently attracts or repels the other. However, there may be sequential competition between the species which would only be important in times of stress, because of the known limited competition for forage. All the above points suggest that the two species can coexist with some manipulation of numbers of both species by man.

\section{Acknowledgments}

We thank members of the Rangelands Research program, Division of Land Resources Management, and of the Division of Mathematics and Statistics for technical assist- 
ance. Comments on the paper by $\mathrm{Dr} G$. Caughley were appreciated. Dr A. E. Newsome is thanked for making available his intimate knowledge of the area and inspiring the writing of this report. The cooperation of the management of Hamilton Downs Station and pilots of Alice Springs Aero Club was essential to the project and is appreciated.

\section{References}

Chippendale G. M. (1968) The plants grazed by red kangaroos, Megaleia rufa (Desmarest), in central Australia. Proc. Linn. Soc. NSW 93, 98-110.

Gwynne M. D. \& Bell R. H. V. (1968) Selection of vegetation components by grazing ungulates in the Serengeti National Park. Nature 220, 390-93.

Hirst S. M. (1975) Ungulate-habitat relationships in a South African woodland/savanna ecosystem. Wildlife Monographs 44, $60 \mathrm{pp}$.
Low B. S. \& Low W. A. (1975) Feeding interactions of red kangaroos and cattle in an arid ecosystem. In: World Conference on Animal Production, Proceedings (Ed. R. L. Reid), pp. 87-94. University of Sydney Press, Sydney.

Low W. A. (1978) History. In: The physical and biological features of Kunoth paddock in central Australia. CSIRO (Aust.) Div. Land Resources Management Tech. Paper No. 4.

Low W. A., Dudzinski M. L. \& Muller W. J. (1981a) The influence of forage and climatic conditions on range community preference of Shorthorn cattle in central Australia. J. Appl. Ecol. 18, 11-26.

Low, W. A., Muller W. J., Dudzinski M. L. \& Low B. S. (1981b) Population fluctuations and range community preference of red kangaroos in central Australia. $J$. Appl. Ecol. 18, 27-36.

Newsome A. E. (1966) Estimating severity of drought. Nature 209, 904.

Newsome A. E. (1975) An ecological comparison of the two arid-zone kangaroos of Australia, and their anomalous prosperity since the introduction of ruminant stock to their environment. Quart. Rev. Biol. 50, 389-424. 
This document is a scanned copy of a printed document. No warranty is given about the accuracy of the copy. Users should refer to the original published version of the material. 